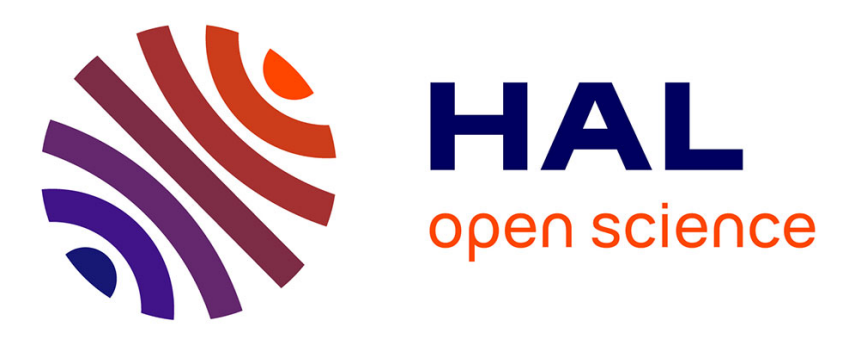

\title{
Towards enhanced durability of electrochromic WO3 interfaced with liquid or ceramic sodium-based electrolytes
}

\author{
Alexandre Zimmer, Manuel Tresse, Nicolas Stein, D. Horwat, Clotilde
}

Boulanger

\section{To cite this version:}

Alexandre Zimmer, Manuel Tresse, Nicolas Stein, D. Horwat, Clotilde Boulanger. Towards enhanced durability of electrochromic WO3 interfaced with liquid or ceramic sodium-based electrolytes. Electrochimica Acta, 2020, 360, pp.136931. 10.1016/j.electacta.2020.136931 . hal-02931228

\section{HAL Id: hal-02931228 \\ https://hal.science/hal-02931228}

Submitted on 12 Jul 2021

HAL is a multi-disciplinary open access archive for the deposit and dissemination of scientific research documents, whether they are published or not. The documents may come from teaching and research institutions in France or abroad, or from public or private research centers.
L'archive ouverte pluridisciplinaire HAL, est destinée au dépôt et à la diffusion de documents scientifiques de niveau recherche, publiés ou non, émanant des établissements d'enseignement et de recherche français ou étrangers, des laboratoires publics ou privés. 


\title{
Towards enhanced durability of electrochromic $\mathrm{WO}_{3}$ interfaced with liquid or ceramic sodium-based electrolytes
}

\author{
Alexandre Zimmer $^{\mathrm{a}, \mathrm{b}, *}$, Manuel Tresse ${ }^{\mathrm{c}}$, Nicolas Stein ${ }^{\mathrm{b}}$, David Horwat ${ }^{\mathrm{c}}$, Clotilde Boulanger ${ }^{\mathrm{b}}$ \\ a Université de Bourgogne, CNRS, ICB, F-21000 Dijon, France \\ ${ }^{\mathrm{b}}$ Université de Lorraine, CNRS, IJL, F-57000 Metz, France \\ c Université de Lorraine, CNRS, IJL, F-54000 Nancy, France
}

\section{ART ICLE INFO}

Article history:

Received 4 May 2020

Received in revised form 10 July 2020

Accepted 8 August 2020

Available online xxx

\section{Keywords}

$\mathrm{WO}_{3}$ thin film

Sodium intercalation

Aqueous medium

NASICON

$\mathrm{Na}^{+}$diffusion coefficient

\begin{abstract}
A B S T R A C T
The reversible intercalation of sodium ion into tungsten oxide $\mathrm{WO}_{3}$ appears as an interesting alternative to hydrogen or lithium ion reduction in order to get the characteristic transition from clear transparent to bluish coloration in electrochromic devices, but it has been comparatively less considered. In order to address further viable all-ceramic devices based on sodium ion intercalation and overcome the issue of $\mathrm{WO}_{3}$ degradation in aqueous media, three configurations of $\mathrm{WO}_{3}$ thin film-based electrochromic half-cells were tested, namely in (i) aqueous acidified $\mathrm{Na}_{2} \mathrm{SO}_{4}$ electrolyte, (ii) room temperature ionic liquid BEPipTFSI electrolyte and (iii) aqueous acidified $\mathrm{Na}_{2} \mathrm{SO}_{4}$ electrolyte associated with an amorphous NASICON-cap onto $\mathrm{WO}_{3}$ film. We compared their electro-optical characteristics during 100 voltammetry cycles, including the $\mathrm{Na}^{+}$diffusion coefficient calculated through electrochemical method. It is found that sputter-deposited amorphous $\mathrm{WO}_{3}$ thin films on transparent conductive substrates is promising for electrochromic all-ceramic devices based on $\mathrm{Na}$ ion insertion. Electrochemical characterization in aqueous medium is not relevant to extract relevant data when $\mathrm{WO}_{3}$ is in direct contact with the electrolyte as the electrochromic film is progressively dissolved. In contrast, $\mathrm{WO}_{3}$ capped with oxide amorphous Na-ion conductor readily operates over 100 cycles, the capping layer preventing degradation by the aqueous medium. Alternatively, ionic liquid does not degrade the $\mathrm{WO}_{3}$ film and can be employed to efficiently characterize the electro-optical performances.
\end{abstract}

\section{Introduction}

Among the most studied types of electrochromic (EC) materials, Tungsten oxide films have widely spanned the EC community due to their ability to switch their optical properties under electrons and monovalent cations intercalation-deintercalation process $\left(\mathrm{WO}_{3}+\mathrm{xM}^{+}+\mathrm{xe}^{-}=\mathrm{M}_{\mathrm{x}} \mathrm{WO}_{3}\right)$ [1]. Applications involving sodium ion conduction are increasingly considered. For instance, due to high abundance of sodium in the Earth crust and low cost electrode, including $\mathrm{WO}_{3}$, sodium ion batteries (SIB) are under development $[2,3]$ whereas e-nose detection popularizes $\mathrm{Na}^{+}$superionic conductor (NASICON) as a solid electrolyte in contact with $\mathrm{WO}_{3}$, among other sensing layers [4,5]. Besides application in EC devices [6], these tungsten trioxide thin films embrace manifold applications e.g. photochromism [7], plasmonics [8], flexible displays [9], gas sensors [10], photocatalysis $[11,12]$ or energy storage material $[13,14]$, sometimes with combined functions $[15,16]$. Despite this rising demand of sodium-

\footnotetext{
* Corresponding author.

E-mail address: alex.zimmer@ellipsometrie.fr (A. Zimmer)
}

based electrochemical devices, the EC community is not yet intensively involved on the synthesis, characterization and development of sodium-based EC devices and individual components. If intercalations of $\mathrm{H}^{+}, \mathrm{Li}^{+}$, or even $\mathrm{K}^{+}$, into $\mathrm{WO}_{3}$ are usually reported they have also some limitations due to hygrometry $\left(\mathrm{H}^{+}\right)$, quantification issues $\left(\mathrm{Li}^{+}, \mathrm{H}^{+}\right)$or poor ionic conduction $\left(\mathrm{K}^{+}\right)$[17]. The intercalation of $\mathrm{Na}^{+}$could then be considered despite its larger cation size $\left(\mathrm{Na}^{+}>r \mathrm{Li}^{+}>r \mathrm{H}^{+}\right)$ and then possible slower associated kinetics. Surprisingly, in the case of $\mathrm{V}_{2} \mathrm{O}_{5}$, a comparison between the cycling behaviors in $\mathrm{LiCl}$ and $\mathrm{NaCl}$ aqueous electrolytes showed higher electrochemical capacity in the latter case, possibly in link with larger surface reaction [18]. Therefore, the development of EC devices based upon Na-intercalated $\mathrm{WO}_{3}$ should not be overlooked before detailed investigation is conducted. If $\mathrm{WO}_{3}$ can readily operate a sodiation-desodiation process using typical three electrodes configuration in aqueous [19-21] or non-aqueous [22-25] electrochemistry, investigations on how to handle the degradation of the amorphous tungsten oxide under potentiodynamic conditions in an aqueous $\mathrm{Na}^{+}$-based medium are lacking. Actually, the degradation in the amorphous case has been suggested $[26,27]$ as originating from very open microstructure with the formation of alkali metatungstate. Then this microstructure would result dissolution by the presence of ac- 
tive sites available for ion-exchange reaction and cycling conditions is considered as voltage enhanced dissolution. Similar processes occurring upon reversible $\mathrm{H}^{+}$and $\mathrm{Li}^{+}$intercalation, conclusions derived from of such investigations could benefit to the entire EC community. Recently electrochemical pre or post-treatments [28-30] have been proposed to increase the durability of Li-based EC-systems. Here we propose alternative ways by capping the active layer or changing the medium for Na-based EC systems.

Dedicated half-cells based on amorphous sputtered films have been considered in our group to assess the feasibility of an all-ceramic EC device based on sodium intercalation using voltammetry cycles $[31,32]$. In the present study, to properly consider the aforementioned degradation in aqueous medium, we propose two alternative configurations to gain information during 100 cycles of coloring-bleaching to be compared to sole moderate acidic $\mathrm{Na}_{2} \mathrm{SO}_{4}$ aqueous medium: (i) a room temperature ionic liquid (BEPipTFSI) instead of the aqueous medium or (ii) the same aqueous medium but with $\mathrm{WO}_{3}$ capped by a NASICON layer leading to isolate $\mathrm{WO}_{3}$ from the direct contact with the aqueous solution. The present paper is dedicated to characterize the electrochemical and optical properties that aims to benchmark the three half-cell configurations and to highlight opportunities to interface $\mathrm{WO}_{3}$ with a ionic liquid or a ceramic ionic conductor in future electrochemical devices.

\section{Materials and methods}

\subsection{Preparation of the $\mathrm{WO}_{3}$ films}

Films were deposited in a 40-1 chamber by direct current magnetron sputtering. Table 1 gives the main parameters for amorphous $\mathrm{WO}_{3}$ films sputtering. More details on the experimental setup can be found elsewhere [33]. $500 \mathrm{~nm}$ Indium Tin Oxide (ITO, $10 \Omega /$ resistance) coated glass substrates were used. These latters were partially masked during the deposition in order to ensure electrical contact to the top side with the ITO layer for cyclic voltammetry purposes. An optimized unique level of oxygen flow was used corresponding to an oxygen substoichiometry of $\sim 0.1$, in order to fulfill mixed conduction condition together with a high visible transmission of the $\mathrm{WO}_{3}$ films [32]. For some of the samples, an amorphous sputtered NASICON cap of $c a$. $300 \mathrm{~nm}$ was deposited on $\mathrm{WO}_{3}$ using $\mathrm{Zr}$-Si and $\mathrm{Na}_{3} \mathrm{PO}_{4}$ target following the procedure described in Refs. [34,35].

\subsection{Electrochemical and optical setups}

Electrochemical measurements were carried out using a VSP-300 potentiostat/galvanostat from Biologic. The electrochemical experiments were performed according a three electrodes configuration as sketched in Fig. 1: (i) the working electrode typically includes a $\mathrm{WO}_{3} / \mathrm{ITO} /$ glass sample capped or not with NASICON which exposes an active surface area of $\sim 2 \mathrm{~cm}^{2}$, (ii) a Pt sheet serves as counter electrode of surface $\sim 1 \mathrm{~cm}^{2}$ (Metrohm), and potentials were given against (iii) a $\mathrm{Ag} / \mathrm{AgCl}$ reference electrode (Bioblock). Two kinds of electrolytes, namely an aqueous solution and room temperature ionic liquid (RTIL), were used to study the cycling properties of a EC half-cell. During the

Table 1

Deposition conditions for RF magnetron sputtering of $\mathrm{WO}_{3}$ thin films.

\begin{tabular}{ll}
\hline Deposition parameter & Sputtering condition \\
\hline Target & 50.8 mm-diameter $\mathrm{WO}_{3}(99.95 \%$ purity $)$ \\
Substrates & centimeter sized ITO-coated glass \\
Power density (W) & 83 \\
Working pressure (Pa) & 4.5 \\
Gas flow rates & typically $85 \mathrm{sccm} \mathrm{Ar,} 1.6 \mathrm{sccm} \mathrm{\textrm {O } _ { 2 }}$ \\
Thickness (nm) & ca. 300
\end{tabular}
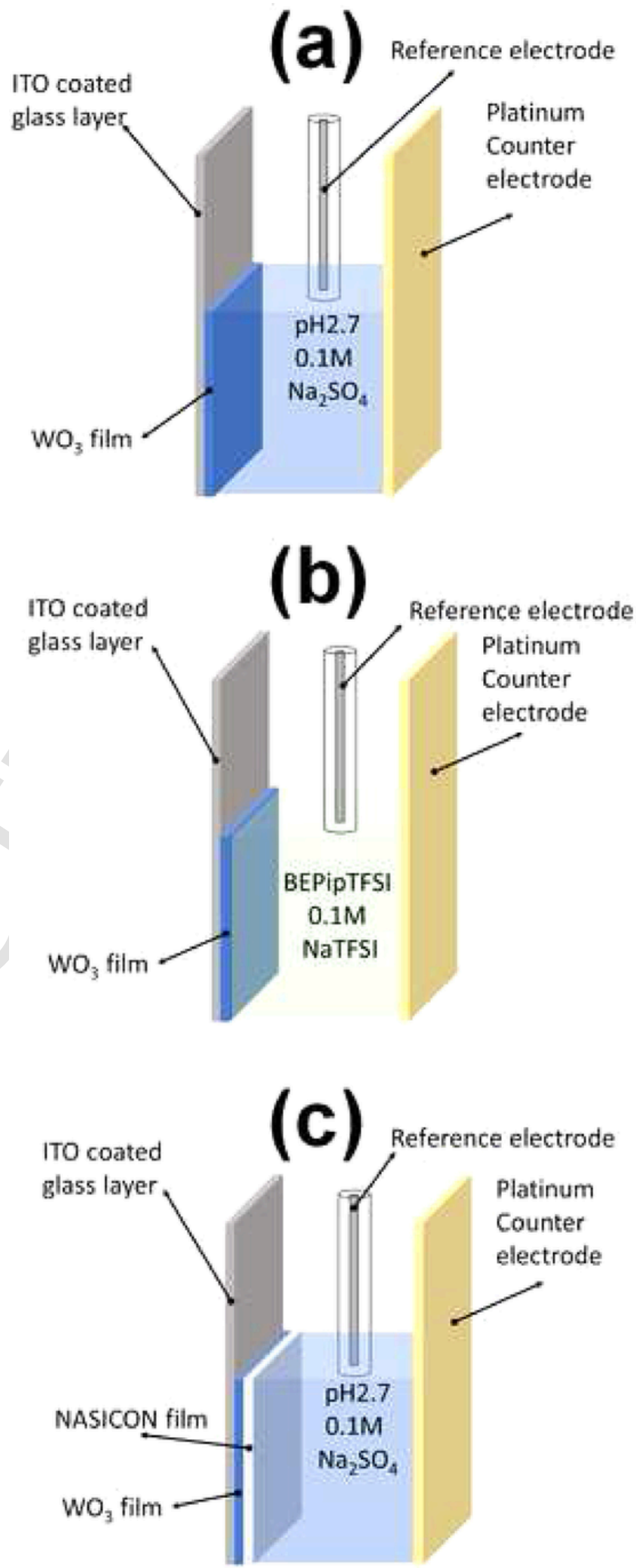

Fig. 1. Experimental setup of the studied EC half-cells: (a) Configuration A: ITO coated glass $/ \mathrm{WO}_{3}$ film $/ \mathrm{Na}_{2} \mathrm{SO}_{4}$ electrolyte/Pt, (b) Configuration B: ITO coated glass $/ \mathrm{WO}_{3}$ film/ BEBipTFSI NaTFSI electrolyte/Pt, (c) Configuration C: ITO coated glass $/ \mathrm{WO}_{3}$ film/NASICON film $/ \mathrm{Na}_{2} \mathrm{SO}_{4}$ electrolyte $/ \mathrm{Pt}$. 
cyclic voltammetry tests, the potential applied at the sample was linearly varied in the range $[-0.65 \mathrm{~V},+0.45 \mathrm{~V}]$. For practical reasons, the potential was measured against the same reference electrode whatever the electrolyte, but no direct comparison of the potential values will be done between the three configurations due to the use of different solvents. The selected aqueous electrolyte was $0.1 \mathrm{M} \mathrm{Na}_{2} \mathrm{SO}_{4}(\geq 99.0$ $\%$, Sigma-Aldrich product) providing a $\mathrm{Na}^{+}$source, being electrochemically inert without any electroactive species. The solution was buffered to $2.7 \mathrm{pH}$ units thanks to a phthalate salt $\left(0.1 \mathrm{M} \mathrm{C}_{8} \mathrm{H}_{5} \mathrm{KO}_{4} / 0.1 \mathrm{M} \mathrm{HCl}\right)$ in order to limit the oxide dissolution as predicted by the Pourbaix diagram of tungsten, which indicates a stable region under $4 \mathrm{pH}$ units [36] and consistent with usual EC device $\mathrm{pH}$ organic electrolyte [37]. Room temperature ionic liquids (RTILs) are attractive electrolytes with several interests particularly the absence of solvent [38]. The used RTIL was composed of 1-butyl,1-ethylpiperidinium with bis(trifluoromethylsulfonyl)imide (BEPipTSI). The latter was chosen for its ability to work in air conditions, having a lower hygroscopic degree than e.g. imidazolium (the maximum content of $\left[\mathrm{H}_{2} \mathrm{O}\right] \simeq 1500 \mathrm{ppm}$ ), and a relatively low viscosity of $290 \mathrm{mPa}$.s [39] in this piperidinium series at room temperature. All the RTILs used in this work were synthesized and purified according to a published procedure [39]. In this non-aqueous solvent, $\mathrm{Na}^{+}$cations were introduced by the addition of $0.1 \mathrm{M}$ NaTFSI $(99.5 \%$, Solvionic). Measurements were conducted without stirring (to simulate real device conditions) and at room temperature. Thus three configurations were experimentally studied according to the following stacks (see Fig. 1):

- Configuration A: ITO coated glass $/ \mathrm{WO}_{3}$ film/ $/ \mathrm{Na}_{2} \mathrm{SO}_{4}$ electrolyte/Pt.

- Configuration $B$ : ITO coated glass/WO $/ \mathrm{WO}_{3}$ film/BEPipTFSI NaTFSI electrolyte/Pt.

- Configuration C: ITO coated glass $/ \mathrm{WO}_{3}$ film/NASICON film/ $/ \mathrm{Na}_{2} \mathrm{SO}_{4}$ electrolyte /Pt.

Transmittance measurements were conducted ex situ (400-800 nm) or in situ $(600 \mathrm{~nm})$, when applicable, using a Varian Cary 5000 spectrophotometer or a Bio-Logic spectrophotometer (SEC2000-UV/VIS) coupled with $\mathrm{a} \sim 1 \mathrm{~cm}^{3}$-electrochemical cell, respectively.

\subsection{Structure, composition and morphology of $\mathrm{WO}_{3}$ films}

The structural properties of the coatings were analyzed by X-ray diffraction (XRD, Bruker Advance D8, $K_{\alpha 1}=1,5406 \AA$ ). Morphological investigations were done by SEM (Philips XL 30S-FEG microscope) and (high resolution) transmission electron microscopy-(HR)TEM (JEM - ARM 200F microscope, including selected area electron diffraction SAED for structural analysis). Elemental analysis was performed by SIMS analysis (Cameca IMS 7F).

\section{Results and discussion}

\subsection{Structural and morphological characterization}

In order to perform an efficient electrochemical cycling, i.e. a reversible sodiation-desodiation process implying a molar volume variation, the as-deposited thin films require porous space to accommodate the structural changes $[40,41]$. Fig.s 2a-c show typical SEM and TEM pictures of as-deposited $\mathrm{WO}_{3}$ thin film. The morphology highlights a columnar growth typical for high pressure deposition with some typical tensile cracks (Figs. 2a and c) [6]. The XRD analysis showed a broad diffraction hump consistent with the amorphous structure of sputtered $\mathrm{WO}_{3}$ in coherence with HRTEM and SAED. Indeed, images are free of crystalline clusters (Fig. 2d, right insert), whereas the electron diffraction signal extracted from SAED consists in a diffuse halo (Fig. 2d, left insert). (a)

(c)

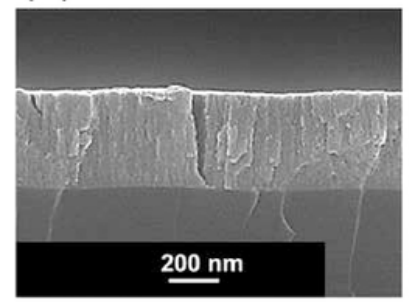

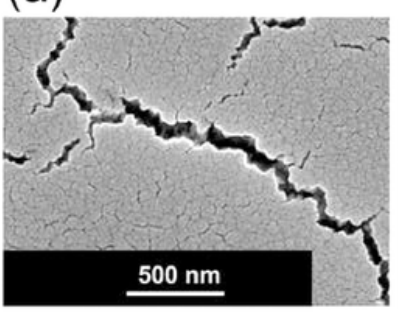

(b)

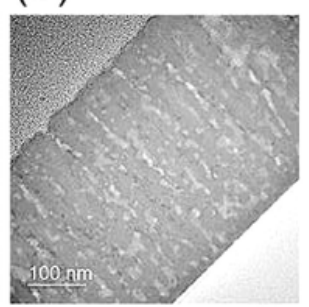

(d)

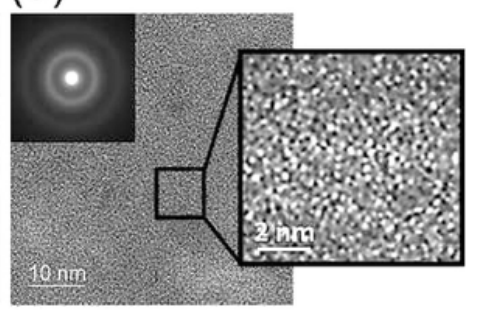

Fig. 2. Representative electron micrographs of sputtered tungsten oxide thin films before $\mathrm{Na}^{+}$insertion: (a) SEM plan view, (b) TEM cross-section view, (c) SEM cross-section view and (d) HRTEM plan view with select area diffraction (left insert) and zoom (right insert).

\subsection{Configuration $A$}

\subsubsection{Preliminary studies}

Following visual observations suggesting a degradation of the thin films at low scan rate $(0.5 \mathrm{mV} / \mathrm{s})$ [31] six different samples were synthetized to optimize the scan rate. Fig. 3a shows the evolution of the second cyclic voltammogram (CV) of the $\mathrm{WO}_{3}$ films characterized with scan rates ranging from 0.5 to $100 \mathrm{mV} / \mathrm{s}$. The data reveal a net difference in the shape of CV in accordance with the literature [42]. Amorphous $\mathrm{WO}_{3}$ films possess a large energetically distributed intercalation sites yielding CV free of distinct peaks [43]. The scan ramp has been fixed to $20 \mathrm{mV} / \mathrm{s}$ range in order to optimize the balance between the following requirements: (i) a good resolution of the electrochemical signal, (ii) the establishment of a quasi-stationary state and (iii) allowing sufficient cycling before the degradation occurs (i.e. as soon as the first cycles $[32,44])$. It appears that the anodic and cathodic peak current densities $\left(\mathrm{j}_{\mathrm{pa}}\right)$ and $\left(\mathrm{j}_{\mathrm{pc}}\right)$ exhibit a linear relation with the square root of the scan rate between $20 \mathrm{mV} / \mathrm{s}$ and $100 \mathrm{mV} / \mathrm{s}$ (Fig. 3a, insert) suggesting a diffusion-controlled process. The diffusion coefficient itself will be discussed in Section 3.4.

It is useful to check whether there is $\mathrm{a} \mathrm{H}^{+}-\mathrm{Na}^{+}$co-intercalation in aqueous medium and to validate the possibility to use the aqueous electrolyte with short residence times to characterize the insertion of $\mathrm{Na}^{+}$ ion. Secondary ion mass spectrometric analyses have been performed on thin films of $\mathrm{WO}_{3}$ in the as-deposited state and after chronoamperometric intercalation at $-0.6 \mathrm{~V}$ in $\mathrm{H}_{2} \mathrm{SO}_{4}(0.1 \mathrm{M}), \mathrm{Na}_{2} \mathrm{SO}_{4}(0.1 \mathrm{M})$ and RTIL containing $\mathrm{Na}^{+}$cations (Fig. $3 \mathrm{~b}$ ). The chosen potential corresponds to a value close to the maximum insertion rate of $\mathrm{Na}^{+}$cations determined from the CV. The RTIL electrolyte only allows sodium cations to be inserted because it does not contain any protons. The profiles obtained are shown in Fig. $3 \mathrm{~b}$ for a measurement time equivalent to probe the thickness of the tungsten oxide film. The first 50 seconds are not to be taken into account; they correspond to the analysis of the extreme surface on which a layer of gold has been deposited to make the sample more conductive. On one hand, the quantities of tungsten (Fig. 3b in green), oxygen (Fig. $3 \mathrm{~b}$ in blue) and hydrogen (Fig. 3b in black) do not change much or not at all i.e., the $\mathrm{WO}_{3}$ film is not altered by the electrochemical analyses. Hydrogen measurements have approximately the same intensity whatever the electrolyte, which means the 

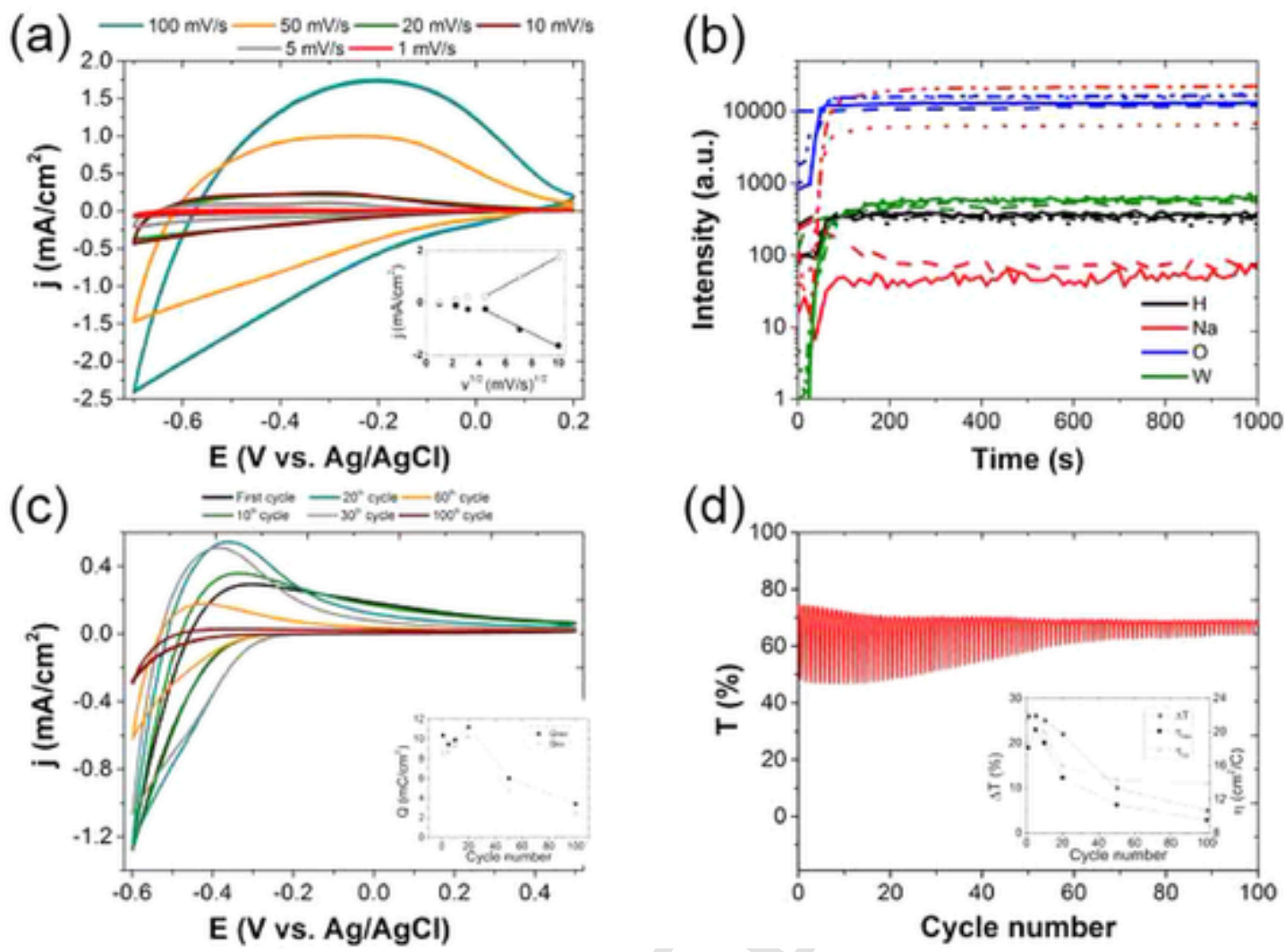

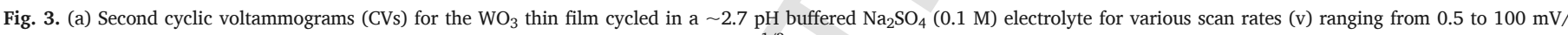

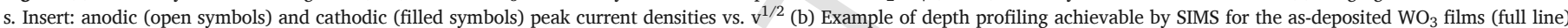

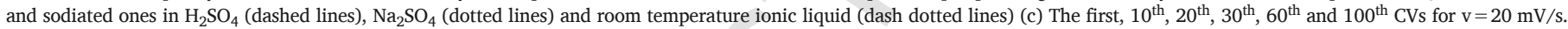

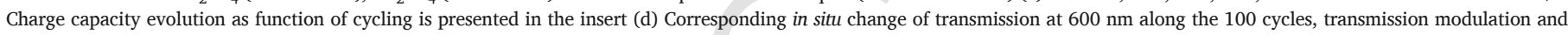
coloration efficiencies as function of cycling are presented in the insert.

inserted protons in aqueous medium $\left(\mathrm{H}_{2} \mathrm{SO}_{4}\right.$ or $\left.\mathrm{Na}_{2} \mathrm{SO}_{4}\right)$ in the film are negligible regarding the moisture content of the film. Note that this humidity can be incorporated during film synthesis because the deposition chamber is not under ultra-high vacuum but also during the transport of the films between the different characterization steps. On the other hand, the amount of sodium (Fig. 3b in red) increases significantly when using sodium-based electrolytes. Although it is impossible to reason with the relative intensities of the elements to access compositions in a quantitative way, it can be deduced that there is an effective insertion of $\mathrm{Na}^{+}$cations by aqueous medium with a negligible influence of proton insertion.

\subsubsection{Electrochromic and optical behavior}

An important optical feature is that the observed characteristic dark blue coloring of the coatings indicates the reduction caused by the intercalation of $\mathrm{M}^{+}$cations $[6,19,21]$. Optical transmission monitoring was preferably performed about $600 \mathrm{~nm}$ which a noticeable absorption of the human eye occurs.

A first practical objective was to define conditions to get representative measurements of the reversible sodiation-desodiation process. The typical cyclic voltammograms (CVs) of a half-cell ITO/ $\mathrm{WO}_{3} / \mathrm{Na}_{2} \mathrm{SO}_{4(\mathrm{aq})} / \mathrm{Pt}$ (configuration $\mathrm{A}$ ) are shown in Fig. $3 \mathrm{c}$ and the corresponding in situ monochromatic transmission $(600 \mathrm{~nm})$ change is shown in Fig. 3d. The overall CV shape evolves in a non-linear way as the cycle number increases. If a peak pattern is observed anodically after 20-30 cycles ("duck" shaping), no clear reduction peak is evidenced as already reported for amorphous $\mathrm{WO}_{3}$ [43] (see also Fig. 3a), except a slight shoulder distinguishable before the water signal. These observations are highlighted by the evolutions of the charge capacities $\left(\mathrm{Q}_{\mathrm{red}}\right.$,
$\left.\mathrm{Q}_{\mathrm{ox}}\right)$ depicted in the insert of Fig. 3c: these capacities are slightly increasing up to the $20^{\text {th }}$ cycle. This can be related to the necessary initial activation process, as invoked in the literature [45]. Over this threshold, $\mathrm{j}$ and $\mathrm{Q}$ values indicate a drastic degradation along the progression of the coloring-bleaching cycles. The electrochemical capacity decreases by more than two thirds of its initial capacity after 100 cycles and reversibility worsens (about only ca. $2.5 \mathrm{mC} / \mathrm{cm}^{2}$ extracted for $4 \mathrm{mC} / \mathrm{cm}^{2}$ injected [Fig. 3c, insert]). In the meantime, the optical transmission evidences a concomitant degradation. Insert of Fig. 3d shows transmission modulation $(\Delta \mathrm{T})$ and coloration efficiencies $\left(\eta_{\mathrm{ox}}, \eta_{\mathrm{red}}\right)$ of $\mathrm{WO}_{3}$ thin film at $600 \mathrm{~nm}$ wavelength, for the $1^{\text {st }}, 5^{\text {th }}, 10^{\text {th }}, 20^{\text {th }}, 50^{\text {th }}$ and $100^{\text {th }}$ cycles deduced from Fig. 3 a-b. $\Delta \mathrm{T}$ can be expressed by

$\Delta T=T_{o x}-T_{r e d}$

where $\mathrm{T}_{\mathrm{ox}}(\%)$ is the transmission of the sample in the bleached state and $\mathrm{T}_{\text {red }}(\%)$ is the transmission of the sample in the colored one. $\Delta \mathrm{T}$ evolution obviously coincides with the decrease of $\mathrm{j}$. Thus the transmittance modulation values evolve from around $25 \%$ in the first cycles to progressively reduce to a level off of $5 \%$ when $\mathrm{j}$ becomes featureless. The coloration efficiencies ( $\eta$ ) can be determined by [46]

$\eta=\frac{\Delta O D}{Q}$

where $\mathrm{Q}$ is the inserted or extracted charge per unit area (Fig. 3c, insert) and $\triangle \mathrm{OD}$ the optical density change of $\mathrm{WO}_{3}$ thin film given by $\Delta O D=\log \left(T_{o x} / T_{\text {red }}\right) . \eta_{\mathrm{Ox}}$ and $\eta_{\text {Red }}$ refer to coloration efficiencies of the oxidation (extraction) and reduction (insertion) processes respectively. $\eta$ value is close to $20 \mathrm{~cm}^{2} / \mathrm{C}$ for the first cycles and decreases with time (Fig. 3d, insert). This value is relatively high, at least in the first $20 \mathrm{cy}-$ 
cles, by comparison to reported values for amorphous sputtered films [47] or lithiated polycrystalline sputtered ones [48].

These data show obviously a significant and concomitant drop of the transmission modulation and of the charge capacity evolution after the $20^{\text {th }}$ cycles. Whatever, the electrochromic process is demonstrated, with performances in agreement with the literature data as displayed by the $20^{\text {th }}$ first values of the coloration efficiencies. Since this rapid and significant decrease of the bleaching-coloration process is probably due to the chemical reactivity of $\mathrm{WO}_{3}$ in aqueous medium (see Refs. $[26,27,44]$ ), alternative configurations were tested in non-aqueous medium (configuration $\mathrm{B}$ ) and with protection outer film (configuration C).

\subsection{Electrochromic and optical behavior in the alternative configurations $B$ and $C$}

Same CV conditions as in the previous section were applied in ionic liquid BEPTFSI including 0.1 M NaTFSI as sodium source. The $\mathrm{WO}_{3}$ thin films operated a reversible switch between a reduced bluish state $(-0.4$ $\mathrm{V})$ and an oxidized bleach one (-0.1 V) [Fig. 4a]. The CVs are outstandingly almost superimposable with the cycles by comparison with configuration A. The electrochemical capacity is slightly decreasing with less $10 \%$ loss after 100 cycles and reversibility remains $\left(Q_{\text {red }}=Q_{o x}\right)$ [see Fig. 4a, insert]. Due to the high viscosity of the RTIL preventing the use of the electrochemical cell for in situ optical measurements, only ex situ transmission spectra were acquired in the full visible range for different states (Fig. 4b). $\Delta \mathrm{T}$ values remain obviously superior to the aqueous case (ca.40\% @ 600 nm whatever the considered cycle vs. $25 \%$ at best in the first cycles of configuration A) and exhibit a good stability. Contrary to the marked degradation observed due to exposure to the aqueous medium of Configuration A, SEM picture released after 400 cycles (not shown) did not evidence change in the surface morphology due to the cyclic sodiation in ionic liquid. It can reasonably be concluded from this result that the quality of the as-deposited thin film is not the cause of the degradation observed in aqueous electrolyte (configuration A). This degradation is rather the result of direct interaction of $\mathrm{WO}_{3}$ with the aqueous electrolyte. The observed stability with time of the electrochemical system in configuration $\mathrm{B}$ and the related bleaching-coloring process indicates that the amount of $\mathrm{WO}_{3}$ available for optical switching remains stable and that the dissolution of the $\mathrm{WO}_{3}$ film seems to be strongly limited in this aprotic ionic liquid, in contrast with aqueous medium $[26,49]$.

The second investigated alternative configuration $\mathrm{C}$ consisted of an amorphous $300 \mathrm{~nm}$-cap of NASICON directly sputtered on the as-deposited $\mathrm{WO}_{3} / \mathrm{ITO} /$ glass sample. If efficient, such a solid barrier layer could offer a way to enable stable sodiation in a widespread aqueous electrolyte, simpler and cheaper than RTILs. Moreover, in the course of optimizing materials performance, such approach could better predict the electrochromic performance of fully ceramic solid device.

Similar CV conditions were used to characterize the duplex electrode $\mathrm{WO}_{3}$ /NASICON (Fig. 4c). A more resistive system is obviously noticed by comparison with the configuration without NASICON (configuration A, Fig. 3c). This observation can be attributed to the additional series resistance of the NASICON layer. Both anodic and cathodic peaks are slightly shifted in the positive direction as the cycle number increases. This results in enlarged difference between peak potentials that can be attributed to a slower kinetic of $\mathrm{Na}^{+}$in presence of the NASICON upper layer. The amounts of inserted and extracted charges increase up to the $30^{\text {th }}$ cycle (Fig. $4 \mathrm{c}$, insert) in probable relation with the aforementioned initial activation process. Then the amounts of
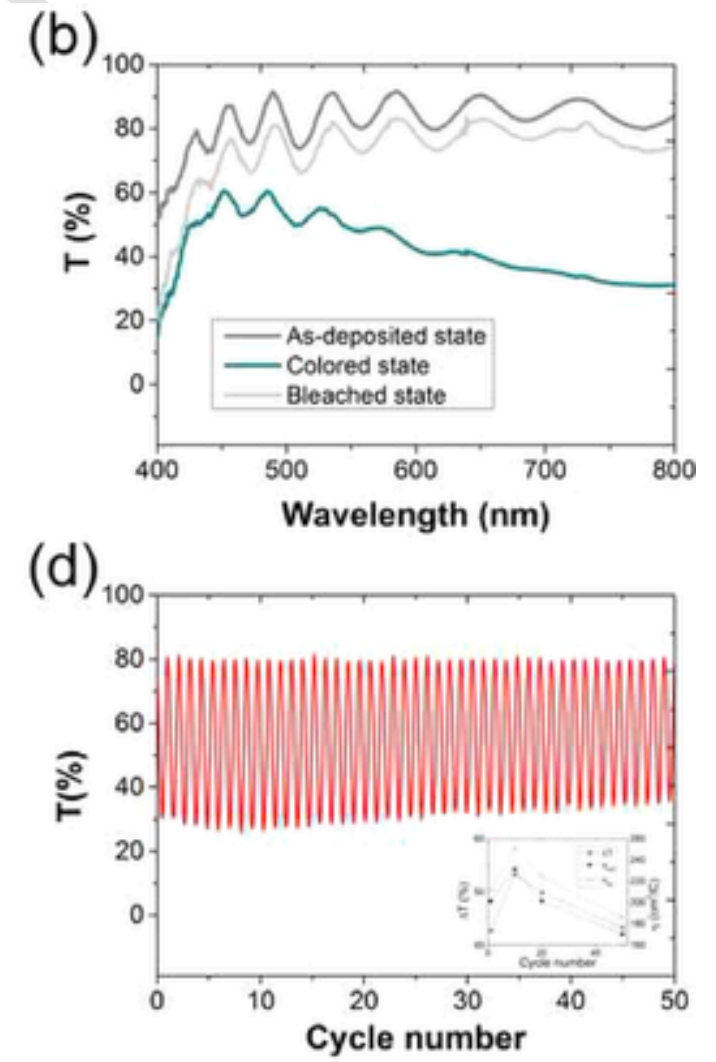

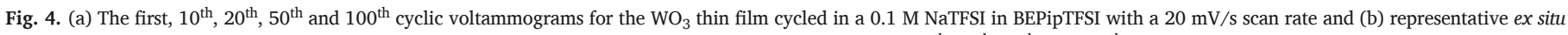

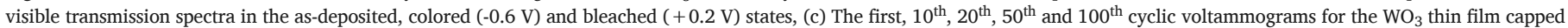

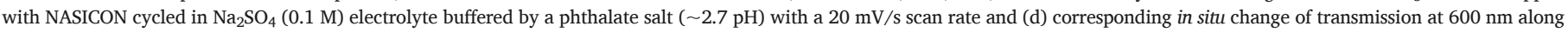
the first 50 cycles. 
charges decrease very little upon cycling, reaching final values very close to those observed in the first cycles and with good reversibility (about ca. $1.8 \mathrm{mC} / \mathrm{cm}^{2}$ extracted for $2 \mathrm{mC} / \mathrm{cm}^{2}$ injected). Optical transmission data are outstandingly stable upon cycling, oscillating roughly between $30 \%$ and $80 \%$ at $600 \mathrm{~nm}$ in the colored and bleached states, respectively (Fig. 4d). These data highlight a good stability and reversibility of the capped system as well as effective reversible transfer of sodium from the aqueous electrolyte to the $\mathrm{WO}_{3}$ layer through the solid electrolyte upon electrochemical cycling.

\subsection{Discussion}

For comparison purposes, Fig. 5 presents, for the three experimental configurations A, B and C, the Coulombic Efficiency (CE), which can be defined as $C E=Q_{o x} / Q_{\text {red. }}$. For the configuration $A, C E$ passes through a maximum around the $10^{\text {th }}$ cycle (93-94\% reversibility, Fig. 5 in blue) and then drops continuously down to less $70 \%$ at $100^{\text {th }}$ cycle, confirming that degradation occurs. Concurrent and concomitant hydrogen intercalation hypothesis has been rejected as verified from SIMS analysis. In order to complete the hypotheses that can be addressed e.g. about the dissolution of the $\mathrm{WO}_{3}$ coating in $\sim 2.7 \mathrm{pH}$ unit buffered conditions, the use of another aprotic electrolyte was tested, i.e. BEPipTFSI, $0.1 \mathrm{M}$ NaTFSI in the configuration B. If the amounts of inserted and extracted charges decrease slightly as function of cycling (Fig. 4a, insert), the CE (Fig. 5 in red) is close to $100 \%$ after the $10^{\text {th }}$ cycle and even equals to $100 \%$ after 100 cycles, showing excellent reversibility. The corresponding $\mathrm{CE}$ transient for the configuration $\mathrm{C}$ (Fig. 5 in black) is almost the same than with configuration B but with $10 \%$ lower values. Thus CE data are nearly stable, not lower than $90 \%$. This stability is confirmed by the evolution of the in situ monochromatic transmission modulation (Fig $4 \mathrm{~d}$ ), revealing typical values of $\Delta \mathrm{T} \sim 50 \%$ in the 50 first cycles i.e. 2 to 5 times higher than in configuration $\mathrm{A}$.

These results show unambiguously that the chemical reactivity of $\mathrm{WO}_{3}$ in water limits the durability of its associated electrochromic behavior. The degradation of the unprotected $\mathrm{WO}_{3}$ film in the aqueous medium starts probably as soon as it is put in contact with electrolyte by progressively lowering $\Delta \mathrm{T}$ values to those usually expected in the literature and comparatively to effectively higher values obtained with the NASICON cap. In the meantime, in situ spectroscopic ellipsometry investigation in our group [44] highlights the role of an excess electrolyte uptake during the cycling resulting progressive film dissolution and leading to highly porous films.

By comparing the $\mathrm{CE}$ values of the three configurations $\mathrm{A}, \mathrm{B}$ and $\mathrm{C}$ (Fig. 5), it may be argued that both alternative configurations $B$ and $\mathrm{C}$ provide efficient solutions to counter-act the degradation in aqueous electrolyte. However, the absolute values of the current density associ-

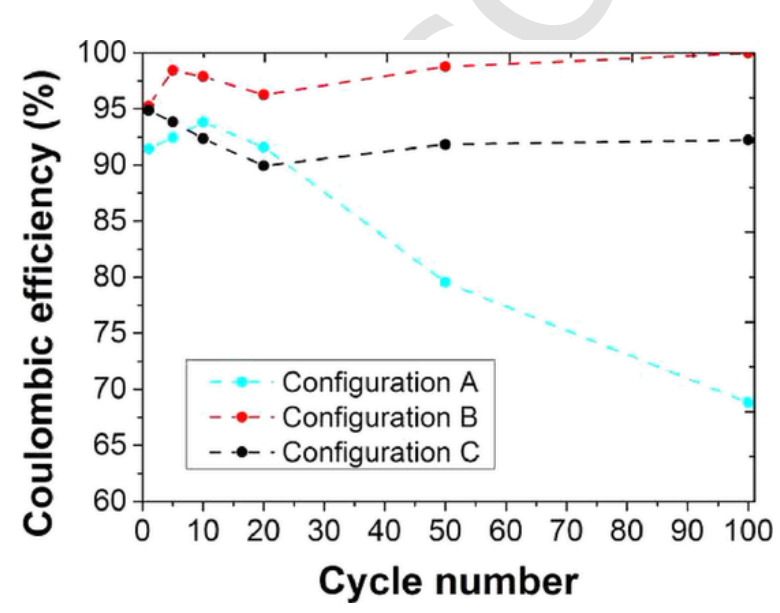

Fig. 5. Influence of the electrolyte on the Coulombic efficiency as a function of cycling. ated to the anodic and cathodic peaks found in both cases, i.e. configuration B and C, are lower comparatively to configuration A. This may be explained by a better penetration of the aqueous electrolyte inside the open morphology of $\mathrm{WO}_{3}$ thin films and then a higher active surface area.

To further compare the electrochemical behaviors of each system, the determined diffusion coefficients (D) of sodium cations were determined for intercalation and deintercalation into the $\mathrm{WO}_{3}$ film, using the Randles-Sevcik method $[19,[50]]$ and gathered in Table 2 as function of cycling. If a decrease of $\mathrm{D}$ values in configuration $\mathrm{A}$ is observed probably in link with the aforementioned degradation in this configuration, the two alternative configurations, namely $\mathrm{B}$ and $\mathrm{C}$, were found very stable also in line with the preserved integrity of $\mathrm{WO}_{3}$ in these configurations. Note that these configurations possess respectively roughly similar (configuration B) and one order of magnitude lower (configuration C) values than for configuration $\mathrm{A}$. The results are in line with the hypothesis that the diffusion coefficients are dependent of the matrix $\mathrm{WO}_{3}$ -cases $\mathrm{A}$ and $\mathrm{B}$ - or $\mathrm{WO}_{3}+\mathrm{NASICON}$-case C- and they are not correlated with the electrolyte. Moreover both D values in the configurations A and $B$ are in the range quoted in literature [24,51-53]. It is also noticeable that the determined $\mathrm{D}$ values for $\mathrm{Na}^{+}$cation $\left(10^{-11}\right.$ to $\left.10^{-12} \mathrm{~cm}^{2} . \mathrm{s}^{-1}\right)$ are close to those reported for $\mathrm{Li}^{+}\left(10^{-9}\right.$ to $\left.10^{-12} \mathrm{~cm}^{2} . \mathrm{s}^{-1}\right)[24,54,55,27]$ or also $\mathrm{K}^{+}\left(10^{-11} \mathrm{~cm}^{2} \cdot \mathrm{s}^{-1}\right)$ [19], in the same $\mathrm{WO}_{3}$ matrix. For the case $\mathrm{C}$, the conductivity of the amorphous NASICON layer was evaluated to be close to $3.10^{-5}{\mathrm{~S} . \mathrm{cm}^{-1}}_{\text {[35] }}$. D values for crystalline NASICON of $2.10^{-3}$ S. $\mathrm{cm}^{-1}$ were evaluated to $5.10^{-10} \mathrm{~cm}^{2} . \mathrm{s}^{-1}$ [56]. Based on that, we can estimate the $\mathrm{D}$ values for the $\mathrm{Na}^{+}$cations in amorphous NASICON capping layer, should be close to $5.10^{-12} \mathrm{~cm}^{2} . \mathrm{s}^{-1}$ and then they are in good agreement with data obtained for configuration $\mathrm{C}$ in this work.

\section{Conclusions}

Electrochromic half-cells based on amorphous sputtered $\mathrm{WO}_{3}$ thin films intercalated by sodium ions have been evaluated in order to compare their electro-optical properties. The simplest case consisting of an aqueous sodium-based electrolyte is limited up to 20 coloration-bleaching switches with CE falling from $\sim 90 \%$ at 20 cycles down to $70 \%$ at 100 cycles. This behavior can be improved with the use of a ion-conducting solid cap (CE 90\%) or with an ionic liquid sodium-based

\section{Table 2}

Determination of sodium-ion diffusion coefficient into $\mathrm{WO}_{3}$ thin films for the three con figurations studied, as function of cycling at $20 \mathrm{mV} / \mathrm{s}$ scan rate. For configuration A, the cathodic peak current density was considered at $-0.5 \mathrm{~V}$.

\begin{tabular}{|c|c|c|c|c|c|}
\hline \multirow[t]{2}{*}{ Configuration } & \multirow[t]{2}{*}{$\begin{array}{l}\text { Cycle } \\
\text { number }\end{array}$} & \multicolumn{2}{|c|}{$\begin{array}{l}\text { peak current densities } \\
\left(\mathrm{mA} / \mathrm{cm}^{2}\right)\end{array}$} & \multicolumn{2}{|c|}{$\begin{array}{l}\mathrm{Na}^{+} \text {diffusion coefficients } \\
\left(\mathrm{cm}^{2} / \mathrm{s}\right)\end{array}$} \\
\hline & & $\mathrm{j}_{\mathrm{pc}}$ & $\mathrm{j}_{\mathrm{pa}}$ & $\operatorname{via} \mathrm{j}_{\mathrm{pc}}$ & via $j_{p a}$ \\
\hline \multirow[t]{6}{*}{ A } & 1 & 0.57 & 0.292 & 2.03E-10 & 5.34E-11 \\
\hline & 10 & 0.59 & 0.357 & $2.18 \mathrm{E}-10$ & 7.98E-11 \\
\hline & 20 & 0.777 & 0.544 & $3.78 \mathrm{E}-10$ & $1.85 \mathrm{E}-10$ \\
\hline & 30 & 0.709 & 0.51 & $3.15 \mathrm{E}-10$ & $1.63 \mathrm{E}-10$ \\
\hline & 60 & 0.3 & 0.176 & $5.63 \mathrm{E}-11$ & $1.94 \mathrm{E}-11$ \\
\hline & 100 & 0.087 & 0.027 & $4.74 \mathrm{E}-12$ & $4.56 \mathrm{E}-13$ \\
\hline \multirow[t]{5}{*}{ B } & 1 & 0.217 & 0.108 & $2.95 \mathrm{E}-11$ & $7.30 \mathrm{E}-12$ \\
\hline & 10 & 0.226 & 0.16 & $3.20 \mathrm{E}-11$ & $1.60 \mathrm{E}-11$ \\
\hline & 20 & 0.23 & 0.16 & 3.31E-11 & $1.60 \mathrm{E}-11$ \\
\hline & 50 & 0.226 & 0.148 & $3.20 \mathrm{E}-11$ & $1.37 \mathrm{E}-11$ \\
\hline & 100 & 0.22 & 0.136 & 3.03E-11 & $1.16 \mathrm{E}-11$ \\
\hline \multirow[t]{5}{*}{ C } & 1 & 0.072 & 0.046 & $3.24 \mathrm{E}-12$ & $1.32 \mathrm{E}-12$ \\
\hline & 10 & 0.083 & 0.052 & $4.31 \mathrm{E}-12$ & $1.69 \mathrm{E}-12$ \\
\hline & 20 & 0.085 & 0.056 & 4.52E-12 & $1.96 \mathrm{E}-12$ \\
\hline & 50 & 0.09 & 0.0615 & $5.07 \mathrm{E}-12$ & $2.37 \mathrm{E}-12$ \\
\hline & 100 & 0.096 & 0.066 & $5.77 \mathrm{E}-12$ & 2.73E-12 \\
\hline
\end{tabular}


electrolyte (CE up to $100 \%$ ) demonstrating the $\mathrm{Na}^{+}$intercalation-deintercalation ability of the sputtered $\mathrm{WO}_{3}$ material. Finally, the small difference in $\mathrm{Na}^{+}$diffusion coefficient is close to reported values for $\mathrm{Li}^{+}$. The $\mathrm{Na}^{+}$cation being more easily quantifiable than $\mathrm{H}^{+}$and $\mathrm{Li}^{+}$by direct measurements, the reported results highlight the interest of $\mathrm{Na}^{+}$ coloring for use in electrochromic systems based on an active layer of the $\mathrm{WO}_{3}$ type or others type like $\mathrm{V}_{2} \mathrm{O}_{5}$ as reported by others $[18,25]$. Moreover, this study underlines that the degradation of $\mathrm{WO}_{3}$ cannot be neglected and leads to wrong evaluation of its electrochromic performance in aqueous medium. Characterizations in ionic liquid or using an ion-conducting outer layer protecting $\mathrm{WO}_{3}$ from the aqueous medium is therefore highly beneficial and recommended.

\section{Uncited references}

[50].

\section{CRediT authorship contribution statement}

Alexandre Zimmer: Writing - original draft, Visualization, Writing review \& editing. Manuel Tresse: Investigation, Formal analysis, Writing - review \& editing. Nicolas Stein: Supervision, Visualization, Writing - review \& editing. David Horwat: Supervision, Writing - review \& editing. Clotilde Boulanger: Supervision, Visualization, Writing - review \& editing.

\section{CRediT authorship contribution statement}

Alexandre Zimmer: Writing - original draft, Visualization, Writing review \& editing. Manuel Tresse: Investigation, Formal analysis, Writing - review \& editing. Nicolas Stein: Supervision, Visualization, Writing - review \& editing. David Horwat: Supervision, Writing - review \& editing. Clotilde Boulanger: Supervision, Visualization, Writing - review \& editing.

\section{Declaration of Competing Interest}

There are no conflicts to declare.

\section{Acknowledgments}

We wish to thank our colleagues Sophie Legeai, Stéphanie Michel and Sébastien Diliberto for fruitful discussions.

\section{References}

[1] C G Granqvist, M A Arvizu, İbayrak Pehlivan, H-Y Qu, R-T Wen, G A Niklasson, Electrochromic materials and devices for energy efficiency and human comfort in buildings: a critical review, Electrochimica Acta 259 (2018) 1170-1182 https://doi.org/, doi:10.1016/j.electacta.2017.11.169.

[2] M Chen, Q Liu, S Wang, E Wang, X Guo, S Chou, High-abundance and low-cost metal-based cathode materials for sodium-ion batteries: problems, progress, and key technologies, Adv. Energy Mater. 9 (2019) https://doi.org/ 1803609, doi:10.1002/aenm.201803609.

[3] F J García-García, J Mosa, A R González-Elipe, M Aparicio, Sodium ion storage performance of magnetron sputtered WO3 thin films, Electrochimica Acta 321 (2019) https://doi.org/ 134669, doi:10.1016/j.electacta.2019.134669.

[4] N Izu, G Hagen, D Schönauer, U Röder-Roith, R Moos, Planar potentiometric SO2 gas sensor for high temperatures using NASICON electrolyte combined with V2O5/WO3/TiO2 + Au or Pt electrode, J. Ceram. Soc. Jpn. 119 (2011) 687-691 https://doi.org/, doi:10.2109/jcersj2.119.687.

[5] X Zheng, C Zhang, J Xia, G Zhou, D Jiang, S Wang, X Li, Y Shen, M Dai, B Wang, Q Li, Sensing properties of amperometric ppb-level NO2 sensor based on sodium ion conductor with sensing electrodes comprising different WO3 nanostructures, J. Mater. Sci. 54 (2019) 5311-5320 https://doi.org/, doi:10.1007/s10853-018-03189-7.

[6] L Pan, Q Han, Z Dong, M Wan, H Zhu, Y Li, Y Mai, Reactively sputtered WO3 thin films for the application in all thin film electrochromic devices, Electrochimica Acta 328 (2019) https://doi.org/ 135107, doi:10.1016/ j.electacta.2019.135107.

[7] C Avellaneda, Photochromic properties of WO3 and WO3:X (X $=\mathrm{Ti}, \mathrm{Nb}$, Ta and Zr) thin films, Solid State Ion 165 (2003) 117-121 https://doi.org/, doi:10.1016/j.ssi.2003.08.023.
[8] L Tegg, D Cuskelly, V J Keast, Plasmon responses in the sodium tungsten bronzes, Plasmonics 13 (2018) 437-444 https://doi.org/, doi:10.1007/ s11468-017-0528-y.

[9] M Rozman, B Žener, L Matoh, R F Godec, A Mourtzikou, E Stathatos, U Bren, M Lukšič, Flexible electrochromic tape using steel foil with WO3 thin film, Electrochimica Acta 330 (2020) https://doi.org/ 135329, doi:10.1016/ j.electacta.2019.135329.

[10] M Penza, M Tagliente, L Mirenghi, C Gerardi, C Martucci, G Cassano, Tungsten trioxide (WO3) sputtered thin films for a NOx gas sensor, Sens. Actuators B Chem. 50 (1998) 9-18.

[11] S-H Baeck, K-S Choi, T F Jaramillo, G D Stucky, E W McFarland, Enhancement of photocatalytic and electrochromic properties of electrochemically fabricated mesoporous WO3 thin films, Adv. Mater. 15 (2003) 1269-1273 https:// doi.org/, doi:10.1002/adma.200304669.

[12] D Raptis, V Dracopoulos, P Lianos, Renewable energy production by photoelectrochemical oxidation of organic wastes using WO3 photoanodes, J. Hazard. Mater. 333 (2017) 259-264 https://doi.org/, doi:10.1016/ j.jhazmat.2017.03.044

[13] H Wang, G Ma, Y Tong, Z Yang, Biomass carbon/polyaniline composite and WO3 nanowire-based asymmetric supercapacitor with superior performance, Ionics 24 (2018) 3123-3131 https://doi.org/, doi:10.1007/s11581-017-2428-8.

[14] V Lokhande, A Lokhande, G Namkoong, J H Kim, T Ji, Charge storage in WO3 polymorphs and their application as supercapacitor electrode material, Results Phys 12 (2019) 2012-2020 https://doi.org/, doi:10.1016/j.rinp.2019.02.012.

[15] H Zheng, J Z Ou, M S Strano, R B Kaner, A Mitchell, K Kalantar-zadeh, Nanostructured tungsten oxide - properties, synthesis, and applications, Adv. Funct. Mater. 21 (2011) 2175-2196 https://doi.org/, doi:10.1002/ adfm.201002477.

[16] X Wu, J Wang, G Zhang, K Katsumata, K Yanagisawa, T Sato, S Yin, Series of M $\mathrm{x}$ WO 3 /ZnO (M = K, Rb, NH 4) nanocomposites: combination of energy saving and environmental decontamination functions, Appl. Catal. B Environ 201 (2017) 128-136 https://doi.org/, doi:10.1016/j.apcatb.2016.08.030.

[17] D Horwat, J Pierson, A Billard, Towards a thin films electrochromic device using NASICON electrolyte, Ionics 14 (2008) 227-233.

[18] I Mjejri, L M Manceriu, M Gaudon, A Rougier, F Sediri, Nano-vanadium pentoxide films for electrochromic displays, Solid State Ion 292 (2016) 8-14 https://doi.org/, doi:10.1016/j.ssi.2016.04.023.

[19] K J Patel, C J Panchal, M S Desai, P K Mehta, An investigation of the insertion of the cations $\mathrm{H}+, \mathrm{Na}+, \mathrm{K}+$ on the electrochromic properties of the thermally evaporated WO3 thin films grown at different substrate temperatures, Mater. Chem. Phys. 124 (2010) 884-890 https://doi.org/, doi:10.1016/ j.matchemphys.2010.08.021.

[20] S V Chong, J L Tallon, Aqueous electrochemical insertion of $\mathrm{Na}+$ into the tungsten oxide hybrid WO3(4,4'-bipyridyl)0.5, J. Phys. Chem. Solids. 71 (2010) 303-308 https://doi.org/, doi:10.1016/j.jpcs.2009.12.081.

[21] A Zimmer, M Gilliot, M Tresse, L Broch, K E Tillous, C Boulanger, N Stein, D Horwat, Coloration mechanism of electrochromic NaxWO3 thin films, Opt Lett. 44 (2019) 1104-1107 https://doi.org/, doi:10.1364/OL.44.001104.

[22] M Green, K S Kang, Variation in the chemical potential of sodium in NaxWO3 thin films, Thin Solid Films. 62 (1979) 385-387 https://doi.org/, doi:10.1016/ 0040-6090(79)90015-4.

[23] E Masetti, D Dini, F Decker, The electrochromic response of tungsten bronzes MxWO3 with different ions and insertion rates, Sol. Energy Mater. Sol. Cells. 39 (1995) 301-307.

[24] D Dini, F Decker, E Masetti, A comparison of the electrochromic properties of WO 3 films intercalated with $\mathrm{H}+, \mathrm{Li}+$ and $\mathrm{Na}+$, J. Appl. Electrochem. 26 (1996) 647-653.

[25] I Mjejri, M Gaudon, A Rougier, Mo addition for improved electrochromic properties of V2O5 thick films, Sol. Energy Mater. Sol. Cells 198 (2019) 19-25 https://doi.org/, doi:10.1016/j.solmat.2019.04.010.

[26] T C Arnoldussen, A Model for Electrochromic Tungstic Oxide Microstructure and Degradation, J. Electrochem. Soc. 128 (1981) 117 https://doi.org/, doi:10.1149/1.2127350.

[27] J Nagai, T Kamimori, M Mizuhashi, Electrochromism in amorphous lithium tungsten oxide films, Sol. Energy Mater. 13 (1986) 279-295.

[28] C G Granqvist, M A Arvizu, H-Y Qu, R-T Wen, G A Niklasson, Advances in electrochromic device technology: multiple roads towards superior durability, Surf. Coat. Technol. 357 (2019) 619-625 https://doi.org/, doi:10.1016/ j.surfcoat.2018.10.048.

[29] M A Arvizu, H-Y Qu, U Cindemir, Z Qiu, E A Rojas-González, D Primetzhofer, C G Granqvist, L Österlund, G A Niklasson, Electrochromic WO 3 thin films attain unprecedented durability by potentiostatic pretreatment, J. Mater. Chem. A. 7 (2019) 2908-2918.

[30] H-Y Qu, E A Rojas-González, C G Granqvist, G A Niklasson, Potentiostatically pretreated electrochromic tungsten oxide films with enhanced durability: electrochemical processes at interfaces of indium-tin oxide, Thin Solid Films 682 (2019) 163-168 https://doi.org/, doi:10.1016/j.tsf.2019.02.027.

[31] M Jullien, Institut National Polytechnique de Lorraine Ph.D. Thesis Nancy, France, 2011.

[32] M. Tresse, PhD. Thesis, Université de Lorraine, Nancy, France, 2016.

[33] M Mickan, U Helmersson, H Rinnert, J Ghanbaja, D Muller, D Horwat, Room temperature deposition of homogeneous, highly transparent and conductive Al-doped ZnO films by reactive high power impulse magnetron sputtering, Sol Energy Mater. Sol. Cells. 157 (2016) 742-749. 
[34] D Horwat, J Pierson, A Billard, Magnetron sputtering of NASICON (Na3Zr2Si2PO12) thin films: Part II: a novel approach, Surf. Coat. Technol. 201 (2007) 7060-7065.

[35] D Horwat, J Pierson, A Billard, Structural-electrical-optical properties relationship of sodium superionic conductor sputter-deposited coatings, Thin Solid Films 516 (2008) 3387-3393.

[36] M Pourbaix, Atlas of electrochemical equilibria in aqueous solution, NACE (1974) 307.

[37] B Faughnan, R Crandall, Electrochromic displays based on WO3, in: J I Pankove (Ed.), Disp. Devices, Springer, Berlin, Heidelberg, 1980, pp. 181-211.

[38] M Galiński, A Lewandowski, I Stępniak, Ionic liquids as electrolytes, Electrochimica Acta 51 (2006) 5567-5580.

[39] J Szymczak, Contribution à l'électrodéposition en milieu liquide ionique de tellurure de bismuth en vue de son dopage $\mathrm{PhD}$. Thesis Université de Lorraine, Metz, France, 2012.

[40] B Reichmann, A J Bard, The electrochromic processat W03 electrodes prepared by vacuum evaporation and anodic oxidation of W, J. Electrochem. Soc. 126 (1979) 583-591.

[41] P R Somani, S Radhakrishnan, Electrochromic materials and devices: present and future, Mater. Chem. Phys. 77 (2002) 117-133.

[42] D T Gillaspie, R C Tenent, A C Dillon, Metal-oxide films for electrochromic applications: present technology and future directions, J. Mater. Chem. 20 (2010) 9585 https://doi.org/, doi:10.1039/c0jm00604a.

[43] W Luo, X K Fu, L H Ma, The research on the high quality TiO2, MoO3-doped WO3 electrochromic film, Chin. Chem. Lett. 18 (2007) 883-886 https:// doi.org/, doi:10.1016/j.cclet.2007.05.003.

[44] A Zimmer, M Gilliot, L Broch, C Boulanger, N Stein, D Horwat, Morphological and chemical dynamics upon electrochemical cyclic sodiation of electrochromic tungsten oxide coatings extracted by in situ ellipsometry, Appl. Opt. 59 (2020) 3766-3772 https://doi.org/, doi:10.1364/AO.389063.

[45] M Kitao, S Yamada, S Yoshida, H Akram, K Urabe, Preparation conditions of sputtered electrochromic WO3 films and their infrared absorption spectra, Sol. Energy Mater. Sol. Cells. 25 (1992) 241-255.

[46] Z Hussain, Optical constants and electrochromic characteristics of $\mathrm{M}_{\mathrm{x}} \mathrm{WO}_{3}$ bronzes, Appl. Opt. 57 (2018) 5720 https://doi.org/, doi:10.1364/ AO.57.005720

[47] M H Kim, T Y Kang, Y S Jung, K H Kim, Electrochromic properties of tungsten oxide films prepared by reactive sputtering, Jpn. J. Appl. Phys. 52 (2013) 05EC03https://doi.org/, doi:10.7567/JJAP.52.05EC03.

[48] M Hutchins, N Kamel, K Abdel-Hady, Effect of oxygen content on the electrochromic properties of sputtered tungsten oxide films with $\mathrm{Li}+$ insertion, Vacuum 51 (1998) 433-439 https://doi.org/, doi:10.1016/ S0042-207X(98)00189-4.

[49] P Judeinstein, R Morineau, J Livage, Electrochemical degradation of WO3• nH2O thin films, Solid State Ion 51 (1992) 239-247.

[50] J Xie, T Tanaka, N Imanishi, T Matsumura, A Hirano, Y Takeda, O Yamamoto, Li-ion transport kinetics in LiMn2O4 thin films prepared by radio frequency magnetron sputtering, J. Power Sources 180 (2008) 576-581.

[51] Edited by M Armand, in: Paul Hagenmuller, W Van Gool (Eds.), Academic Press, New York, 1979 Edited by.

[52] G Garcia-Belmonte, J García-Cañadas, J Bisquert, C Person, Jump diffusion coefficient of different cations intercalated into amorphous WO3, Solid State Ion 177 (2006) 1635-1637.

[53] C A C Sequeira, L F F T T G Rodrigues, D M F Santos, Cation diffusivity in nonstoichiometric tungsten trioxide films, ECS J. Solid State Sci. Technol. 1 (2012) R136-R139 https://doi.org/, doi:10.1149/2.010205jss.

[54] M L Hitchman, Photon diffusion in hydrogen tungsten bronzes, Thin Solid Films 61 (1979) 341-348.

[55] C Ho, Application of A-C techniques to the study of lithium diffusion in tungsten trioxide thin films, J. Electrochem. Soc. 127 (1980) 343 https:// doi.org/, doi:10.1149/1.2129668.

[56] F Mauvy, Reactivity of NASICON with water and interpretation of the detection limit of a NASICON based Na + ion selective electrode, Talanta 48 (1999) 293-303 https://doi.org/, doi:10.1016/S0039-9140(98)00234-3. 